ries") of pencil sharpeners to be found in various parts of the library although they all somehow neglected to adequately describe how to locate the proper place to insert the pencil. As cited in slightly more detail in my earlier piece on the peculiar nature of music librarians, Stephen Fry, of the Music Library, concluded that three-part series with a longer than usual description of one gray Apsco "Giant" type III-A sharpener there that, in the usual perverse fashion of music librarians, had been installed in such a way that it is especially handy for left-handed people who were invited there just for that purpose.

A favorite sport of some law librarians, following an example set by one of the deans of their profession, is to offer law faculty and, especially, students the opportunity to ask written questions on any matter that strikes their fancy in a public notebook to which the law librarian himself, or herself as the case may be, subsequently responds in writing for all to read and be entertained by. In his notebooks Robert Berring, law librarian at the University of California, Berkeley, who started the whole thing, found two items relating to the important question of pencil sharpeners. One student asked what those "little bits of disgusting pencil shavings" that he finds on desks are and why people don't have the courtesy to clean up after themselves. Zeb, for so the respondent styles himself, pointed out that those are not, in fact, pencil shavings but "tiny bits of the outer layer of the brain stem" that "most first year law students shed...as a part of the first year process of acculturation." Those chips, which are highly toxic and not to be ingested, are collected and sold for reprocessing into memory chips for super computers. Another user asked Zeb if the fact that the electric pencil sharpeners always break is a plot. Zeb replied that it indeed was a plot that is part of a long-term clinical psychological study in frustration levels and that, actually, most of those sharpeners never actually worked at all.
Emily Greenberg, one of Berring's imitators, of the University of Baltimore Law Library, was asked by a student: "Is it possible to have a pencil sharpener installed on the fourth floor?" In her rather lengthy answer Ms. Greenberg analyzes the usual bureaucratic delays involved in the purchase process-even for something as simple as a pencil sharpener-and the several difficult problems faced in the selection of the ideal location: noise ("that old-fashioned non-electric hand-crank machine is going to upset some patrons"); eyes, ears, and other body parts ("you have to mount the machine at a height where even short people can reach it"); and aesthetics ("it grieves me to think of sullying the horizon with a little metal protuberance"). Ms. Greenberg ultimately concedes that a pencil sharpener will eventually be installed on the fourth floor.

The most intriguing library anecdote involving pencil sharpeners, which comes-alas-from a public library setting, is a brief tale recounted by Anita Gregory who now works at the Occidental College Library. In her earlier life as a public librarian Ms. Gregory once encountered a patron who came to the Circulation Desk and asked for the location of the men's room. "He was informed [Ms. Gregory writes] that it was kept locked, for his safety, and that the key was missing. He blinked, and without missing a beat, asked, 'Well then, do you have a pencil sharpener?'”

\section{Conclusion}

Surely if librarians can keep a straight face when faced with such improbable relationships, we can master any form of technology. The higher forms may broaden our horizons, expand our services, and offer our patrons entry into new forms of knowledge. The lower forms continue to limit our capabilities, restrict our services, and offer us entry into new forms of amusement.

\title{
Telephone information service
}

\author{
By Edward A. Riedinger
}

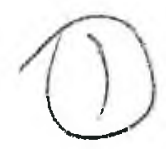

School of Library and Information Studies
University of California, Berkeley

The literature on telephone information or reference service has concentrated on this activity primarily as it is conducted in public library settings. Such research has been appearing for over half a century. However, telecommunication changes now occurring in academic libraries, from junior and community colleges to major research universities, will heighten the importance of telephone information service in them.

Online collection catalogs are now common- 


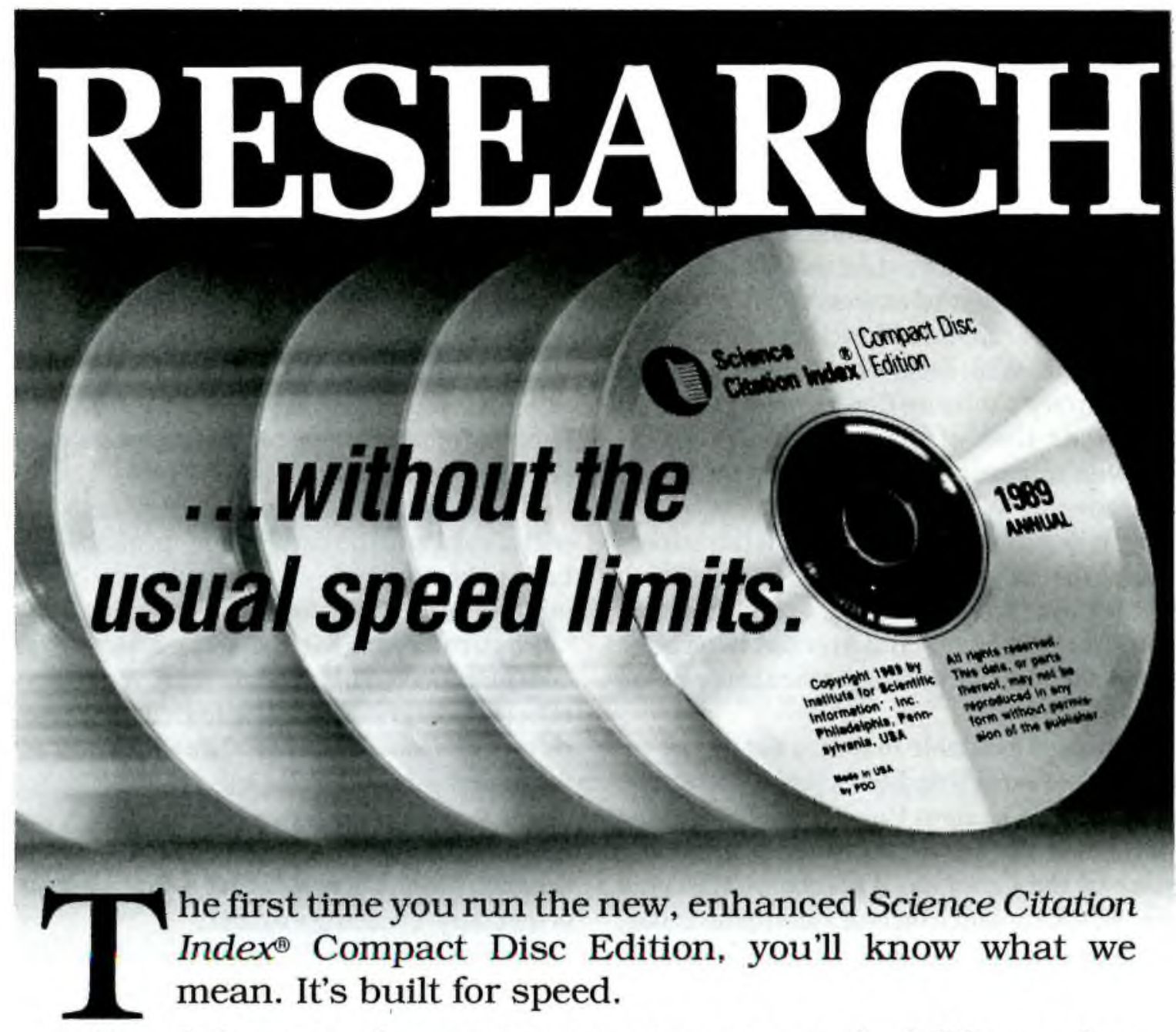

Speed that translates into instant access to the bibliographic data from 3300 sci-tech journals. The journals you depend on to keep your research going full speed ahead.

But the CD Edition does more than go faster-it goes farther. An exclusive hypertext feature called related records leads you to other records having references in common with the ones you've already retrieved ... expanding your search with a few simple keystrokes.

And even though Laserdisk Professional magazine named the SCI ${ }^{\circledR}$ CD Edition "Product of the Year," we went back and made it better. Now on a single disc, it's easier than ever to use.

Call us toll-free at: 800- 523-1850, ext. 1405 or write us at the address below to reserve your free trial copy.

Find out what it's like to work without speed limits.

Science Citation Index $\mid$ Edition
Institute for Scientific Information 3501 Market Street

Philadelphia, PA 19104 U.S.A. 
place in libraries. What is emerging as another common practice is accessing these catalogs via a modem from a user's personal computer. At any time of day (or night) and from virtually any location, a scholar can browse a university catalog and, having a printer, make a copy of the information found.

However, besides examining a collection catalog, the online user can now access other information in a library's database, such as an encyclopedia, periodical literature guide, current news index, or other file. As a result, the online user can examine a considerable amount of extensive reference resources from an academic library (or libraries) in his or her home. With this information a user can phone the library's information/reference desk (at an appropriate time of day) and confer on the material with a librarian. Consequently, the nature of the academic telephone reference inquiry is changing. It is assuming more of the characterisitcs of a traditonal face-to-face interview since both user and librarian have the same catalog and reference resources "at hand." If a user has two phone lines, he or she could be looking at the same catalog screen as a librarian.

The resources available in online databases are becoming more extensive. For example, the online catalog of the nine-campus University of California system (MELVYL) incorporates the catalogs and databases of the Colorado Alliance of Research Libraries (CARL), which includes an articles index, an encyclopedia (the electronic equivalent to 20 volumes), and numerous other reference files.

Accessing these growing resources proves greatest among the academic community. This group is one of the largest segments in the general population most likely to have or use personal computers, modems, catalogs, and databases.

Academic libraries must begin to think, therefore, in terms of more extended and sophisticated use of telephone information and reference services. For the first time in the history of this service, emphasis is beginning to shift from public to academic libraries. Some of the literature on this service as conducted in public libraries can be conveniently adapted for college and university libraries.

There are already two books, recently published, that should prove quite helpful to this adaptation since they are as comprehensive as they are relevant. These works are A Librarian's Guide to Telephone Reference Service (Hamden, Conn.: Library Professional Publications, 1986) by Rochelle Yates and Improving Telephone Information and Reference Service in Public Libraries (Hamden, Conn.: Library Professional Publications, 1987) by Rosemarie Riechel.

The former is especially helpful in terms of training, publicity and promotion, and evaluation for a telephone service. The latter is particularly useful in setting up the resources for such a service, including online facilities.

There are some key areas in which academic reference services can already begin to plan. One of these is user policy and how identification will be made of those who are allowed to use the telephone service. Online user access codes or I.D.'s may have to be developed. Policy concerning users will differ between private and public universities. Among the latter there will also be differences between community colleges and state institutions.

Regarding policy for the areas in which responses will be given to inquirers, no doubt guidelines concerning this issue will follow the library's collection policy. This probably will have been formulated to follow the teaching and research fields of the college or university.

How long a phone inquiry is allowed to continue will also have to be determined. In addition, it will have to be decided the extent to which homework inquiries will be answered.

Physical space for the service is another key consideration. The fundamental requirement is efficient integration of all resources, librarian with reference resources, and printed resources with those that are online. It must always be remembered that physical space defines the telephone service in order to secure not only the materials necessary for its operation but to indicate that there is specially-trained personnel.

Preparation of staff for phone reference work must balance efficient with careful response. A salient characteristic of the new type of academic telephone reference work will be the fact that both user and librarian are referring to and consulting materials that neither is using in the presence of the other. Training, therefore, must emphasize not only active listening but also knowledge of a kind of "braille orientation." The librarian will not "see" how an inquirer is using materials but will have to "feel" the sense that is being made of them (until videophone, of course). Instructions to the user regarding additional resources for clarifying or further pursuing a question will become more important.

Statistics regarding users should include the type of resources used and their importance in the response. This descriptive statistical attention is important because it is new resources that are determining the expanding and more complex character of telephone service. These statistics will, therefore, not only profile and verify the phenomenon but be the basis for identifying resources to be strengthened in future development of it.

Academic libraries at all levels are going to find telephone inquiries becoming more complex due to the density of reference content they include. Much of this density will be due to online refer- 
ences the user and librarian can access in common. We are currently in a fortuitious position to begin already planning for and thinking of the innova- tions necessary for this technological and historical change in academic library reference service.

\title{
Librarians: An element of diversity
}

\section{within the faculty}

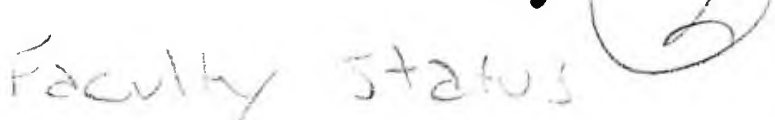

\author{
By Diane C. Parker \\ Director of Libraries \\ Western Washington University
}

\section{One librarian's answer to the question, "Why are librarians} faculty?"

4

t any college or university, librarians tend

to be a small percentage of the faculty, perhaps $3 \%$ to $4 \%$ of the whole. It is easy for a such a small group to become relatively unnoticed and not widely understood. In fact, librarians provide an element of diversity within the faculty. They are the same as other faculty in fundamental nature, but differ in the form and scope of their professional activity.

\section{A. The fundamental similarities}

1. Faculty are involved with the life of the mind. They interact with others to share and extend the realm of knowledge.

2. Faculty are engaged with the subject matter of the academy.

3. Faculty are involved with teaching others.

4. The career development of faculty members is based on incremental accomplishments culminating in a high level of professional maturity and contribution to the furtherance of knowledge. Their promotion to senior ranks depends on enhanced mastery of their discipline within a position, rather than changing job assignments.

\section{B. Patterns of engagements}

Instructors and librarians differ in their patterns of engagement with the fundamentals. Some of the various patterns are described below:

1. While instructors focus more on the content of a discipline, librarians focus more on the structure of disciplines and how they are organized.

2. Librarians collect and organize materials into coherent collections so that instructors and students can find specific items and browse through subject matter easily. The librarian's perspective on knowledge tends to be encyclopedic, with concern for the whole universe of knowledge.

3. Instructors are professionally committed to academic freedom with its principles of the right to profess a point of view, provided that it is done responsibly. Librarians are professionally committed to intellectual freedom with its principles of providing a neutral forum for diverse points of view.

4. While instructors provide a disciplinary inter- 